Research Article

\title{
Comparison of Endothelial Cell Loss following the Big Bubble versus the Microbubble Incision Technique during Deep Anterior Lamellar Keratoplasty in Eyes with Keratoconus
}

\author{
Amro Abuelkheir, Mohamed Bahgat Goweida, Nada Medhat, and Hany Ahmed Helaly \\ Department of Ophthalmology, Faculty of Medicine, Alexandria University, Alexandria, Egypt \\ Correspondence should be addressed to Hany Ahmed Helaly; hany209209@yahoo.com
}

Received 2 June 2020; Accepted 2 November 2020; Published 11 November 2020

Academic Editor: Suphi Taneri

Copyright (c) 2020 Amro Abuelkheir et al. This is an open access article distributed under the Creative Commons Attribution License, which permits unrestricted use, distribution, and reproduction in any medium, provided the original work is properly cited.

\begin{abstract}
Introduction. Deep anterior lamellar keratoplasty (DALK) is now becoming an increasingly popular surgical technique in treating corneal stromal pathologies with healthy endothelium. Several advantages of DALK over penetrating keratoplasty (PKP) have been described such as maintenance of globe integrity, absence of endothelial rejection, and a low rate of chronic endothelial cell loss (ECL). ECL following PKP results in 50\% cell loss after 2 years from the estimated graft endothelial cell density (ECD). Although there are several reports confirming that ECL following DALK is similar to the physiologic cell loss 2 years after surgery, few reports discussed the surgically induced ECL due to difficulty in preoperative imaging of ECD. Materials and Methods. This prospective, interventional study included 20 eyes of 20 patients, who underwent DALK surgery. 11 eyes underwent DALK using the big bubble technique, while 9 eyes underwent the microbubble technique. Postoperative evaluation was done 3 months after surgery and included best spectacle corrected visual acuity (BSCVA), keratometric readings, and refraction measured using an autokeratorefractometer (Topcon KR800, Japan) and endothelial cell density (ECD) using noncontact specular microscopy (Nidek CEM-530, Japan). Results. Regarding postoperative parameters such as postoperative logMAR visual acuity, postoperative mean $\mathrm{K}$, and postoperative $\mathrm{K}$ max, there was no statistical difference found between both groups $(P=0.754, P=0.119$, and $P=0.970$, respectively). Regarding change in specular endothelial cell density and percent change in the specular endothelial cell density, again there was no statistical difference between both groups with $P=0.057$ and $P=0.126$, respectively (significance defined as $P<0.05)$. Conclusion. ECD is not affected by failure of the big bubble to form and continuing DALK via the microbubble technique.
\end{abstract}

\section{Introduction}

Penetrating keratoplasty (PKP) has been the treatment of choice for advanced cases of keratoconus for a long time [1-3]. During the past decade, however, because of advancement in surgical techniques, deep anterior lamellar keratoplasty (DALK) has gained popularity in the treatment of keratoconus $[3,4]$.

Comparative studies with PKP have shown overall similar visual outcomes when both techniques are used. Several advantages of DALK over penetrating keratoplasty (PKP) have been described such as maintenance of globe integrity, early suture removal, absence of endothelial rejection, and a low rate of chronic endothelial cell loss (ECL) $[5,6]$.

Anwar and Teichmann proposed a technique, which they called the big bubble technique, where air is injected into the deep stroma with the aim of inducing separation by cleavage between posterior stroma and the DM, allowing the surgeon to gain a safe and direct access to this plane, with the advantages of shortening the surgical time, reducing the risk of perforation, and exposing a smooth, even surface of excellent optical quality [7].

One surgical problem with big bubble DALK is the variable success rate in achieving a big bubble, which varies between $50 \%$ and $90 \%$ in several studies [8-10]. Surgeons 
should resort to alternative techniques, in eyes with failed BB formation, such as layer-by-layer dissection, viscodissection, hydrodelamination, and the microbubble (MB) incision technique [11-14].

In normal eyes, $0.6 \%$ of the endothelial cells are lost every year [15]. Corneal endothelial cell loss after penetrating keratoplasty occurs at a higher than physiologic rate to a cumulative cell loss of $50 \%$ or more within the first 10 years. This suggests that, after the initial surgical trauma, donor endothelial cell survival is compromised in the host ocular environment $[16,17]$.

Deep anterior lamellar keratoplasty has been associated with lower levels of endothelial cell loss compared with penetrating keratoplasty. This may be because of the reduced surgical trauma in DALK compared with penetrating keratoplasty and the absence of endothelial cell rejection in patients undergoing DALK $[18,19]$.

Although there are several reports confirming that ECL following DALK is similar to the physiologic cell loss 2 years after surgery, few reports discussed the surgically induced ECL due to difficulty in preoperative imaging of ECD [20].

We herein report the surgically induced ECL following DALK comparing 2 techniques, the $\mathrm{BB}$ and the $\mathrm{MB}$ incision techniques.

\section{Patients and Methods}

This prospective, interventional study included 20 eyes of 20 patients. The study was conducted in accordance with the tenets of the Declaration of Helsinki and was approved by the Institutional Ethics Committee in Alexandria University.

\subsection{Inclusion Criteria}

(1) Patients with stromal corneal pathologies and poor best corrected visual acuity (BCVA)

(2) Healthy corneal endothelium

(3) Reliable specular imaging of either eye

\subsection{Exclusion Criteria}

(1) Coexistent ocular pathology or previous ocular surgery

(2) Corneal scarring involving Descemet's membrane (DM)

(3) Advanced disease interfering with specular evaluation in either eye

(4) Patients with intraoperative perforation of DM

2.3. Pre- and Postoperative Assessments. Informed consent was obtained from the patients that were included in the study after explanation of the details of the study and of the procedure to be performed.

Preoperative evaluation included the patient's disease history, BCVA measured using the standard Snellen chart and converted to logarithm of the minimum angle of resolution (logMAR) for statistical analysis, slit-lamp microscopy, fundus examination, Pentacam evaluation of the cornea using the Allegro Oculyzer (WaveLight; Alcon, Erlangen, Germany), and ECD using noncontact specular microscopy (Nidek CEM-530, Japan). In eyes with advanced disease interfering with proper image acquisition, the fellow eye is used as a reference to the preoperative ECD.

Postoperative evaluation was done 3 months after surgery and included BCVA, Keratometric readings and refraction measured using an autokeratorefractometer (Topcon KR800, Japan) and ECD.

2.4. Surgical Technique. All surgeries were performed using the $\mathrm{BB}$ technique, previously described by Anwar and Teichmann [7] with some modifications from the original technique, such as performing a paracentesis before bubble formation to inject small air bubbles in the anterior chamber and using a Fogla 27-gauge air injection cannula (Bausch and Lomb, Rochester, NY) to create the BB.

Eyes with failed big bubble formation after multiple trials of intrastromal air injection were managed using the $\mathrm{MB}$ incision technique previously described by Riss et al. [14].

2.5. Postoperative Medications. Patients received topical gatifloxacin (Zymar, Allergan, Irvine, California, U.S.A) every 6 hours for 30 days and topical prednisolone (Pred Forte, Allergan, Irvine, California, U.S.A) every 6 hours tapered over 2 to 3 months and then replaced by topical fluormetholone (Flucon, Alcon Laboratories, Fort Worth, Texas, USA). Topical lubricants were administered to hasten epithelial healing. Bandage contact lens fitting was done to treat nonhealing epithelial defects.

Follow-up examinations were scheduled 1, 3, 7, and 30 days and 3 and 6 months postoperatively.

2.6. Statistical Analysis. Data were fed to the computer and analyzed using IBM SPSS software package version 20.0 [21]. Qualitative data were described using number and percent. Quantitative data were described using range (minimum and maximum), mean, standard deviation, and median. Significance of the obtained results was judged at the $5 \%$ level.

\section{Results}

This study included 20 eyes of 20 patients, 11 eyes were operated via the $\mathrm{BB}$ technique (BB group), while in 9 eyes, the $\mathrm{MB}$ incision techniques were used due to failure of $\mathrm{BB}$ formation (MB group).

The mean patient age was $23.73 \pm 6.96$ years in the $\mathrm{BB}$ group (range 15-40 years) and $26.44 \pm 9.41$ years in the $\mathrm{MB}$ group (range 12-43 years). There were 3 males and $8 \mathrm{fe}$ males in the BB group, while 7 males and 2 females were present in the MB group. The difference in age and gender distribution was statistically nonsignificant between the two groups: $P=0.467$ and $P=0.07$, respectively.

By using Mann-Whitney nonparametric test to compare the mean rank of preoperative logMAR visual acuity 
Table 1: Preoperative and postoperative parameters in the two groups.

\begin{tabular}{lccc}
\hline & $\begin{array}{c}\text { Big bubble group, mean } \pm \text { standard deviation } \\
\text { (mean rank) }\end{array}$ & $\begin{array}{c}\text { Microbubble group, mean } \pm \text { standard deviation } \\
\text { (mean rank) }\end{array}$ & $P$ value \\
\hline $\begin{array}{l}\text { Preoperative } \\
\text { logMAR }\end{array}$ & $1.2891 \pm 0.11004(12.50)$ & $1.0467 \pm 0.30265(8.06)$ & \\
Postoperative & $0.3145 \pm 0.15391(10.86)$ & $0.2767 \pm 0.11203(10.06)$ & $0.039^{*}$ \\
logMAR & $4.0455 \pm 2.86782(11.73)$ & $3.3600 \pm 2.12522(9.00)$ & 0.754 \\
$\%$ change in BCVA & $59.7500 \pm 2.86575(11.45)$ & $58.6667 \pm 3.85681(9.33)$ & 0.297 \\
Preoperative mean $K$ & $44.9673 \pm 1.94272(12.36)$ & $43.5444 \pm 2.62748(8.22)$ & 0.423 \\
Postoperative mean & $0.3309 \pm 0.08006(10.23)$ & $0.3544 \pm 0.13116(10.83)$ \\
$K$ & $69.8182 \pm 3.73679(10.68)$ & $70.3333 \pm 6.59545(10.28)$ \\
\% change of mean $K$ & $45.9545 \pm 1.49088(10.45)$ & $45.9444 \pm 1.64781(10.56)$ & 0.119 \\
Preoperative $K$ max & $0.5209 \pm 0.07120(10.27)$ & $0.5289 \pm 0.11352(10.78)$ \\
Postoperative $K \max$ & \% change of $K \max$ & & 0.879 \\
\hline
\end{tabular}

Significance between groups was obtained using Mann-Whitney test. $*$ Statistically significant at $P<0.05$.

TABLE 2: Comparing both groups regarding specular endothelial cell density (ECD).

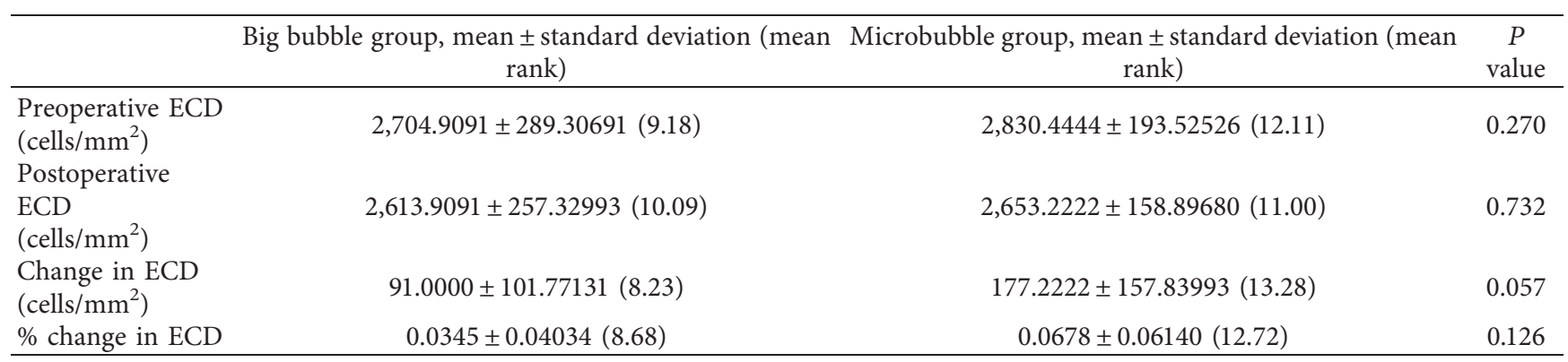

Significance between groups was obtained using Mann-Whitney test. $*$ Statistically significant at $p \leq 0.05$.

between the big bubble group (12.50) and the microbubble group (8.06), there was a statistical difference between the mean ranks of the two groups $(P=0.039)$ (statistical difference considered at $P<0.05)$.

By analysis of the preoperative parameters including preoperative mean keratometric reading (mean $K$ ) and preoperative maximum keratometric reading $(K \max )$ and comparing their mean ranks in both groups, no statistical difference was found $(P=0.423$ and $P=0.879$, respectively).

As for postoperative parameters such as postoperative $\log$ MAR visual acuity, postoperative mean $K$, and postoperative $\mathrm{K} \max$, there was no statistical difference found between both groups $(P=0.754, p=0.119$, and $P=0.970$, respectively) Table 1 .

Comparing preoperative and postoperative endothelial cell density (ECD) between both groups showed that there is no statistical difference regarding the mean rank of the preoperative and postoperative ECD between both groups using Mann-Whitney nonparametric test $(P=0.270$ and $P=0.732$, respectively).

Regarding change in specular endothelial cell density and percent change in the specular endothelial cell density, again there was no statistical difference between both groups with $p=0.057$ and $P=0.126$, respectively (significance defined as $P<0.05)$ Table 2.

Testing, if there is a relation between the percent change in specular endothelial cell density (ECD) and percent change in mean $\mathrm{K}$, proved that there is a negative relation between both with correlation coefficient equals -0.450 $(P=0.047)$ (correlation is significant at the 0.05 level) using spearman correlation test.

\section{Discussion}

Sufficient corneal endothelial cell density is required for long-term functional success of any type of keratoplasty. With penetrating keratoplasty, an overall endothelial cell loss has been reported of approximately $33 \%$ within the first 2 postoperative years and that the cell density continues to decrease at an accelerated rate up to 20 years after surgery $[13,16,22-24]$.

Following DALK surgery, endothelial cell loss due to allograft rejection decreases substantially. Sugita et al. [13] reported that endothelial cell loss after DALK was 13\% at the end of first year. Van Dooren et al. [25] found that ECD showed an $11 \%$ decrease during the first six months after DALK, and afterwards, the decrease was $1 \%-2 \%$ per year. They also found that the decrease in ECD was similar to that of nonoperated healthy corneas [25]. Among the reasons for large decreases in ECD after DALK surgery, perioperative air injection into the anterior chamber and trauma of the recipient endothelium during deep stromal dissection has been proposed $[25,26]$.

No study was done to evaluate the effect of surgical trauma of various techniques of DALK on the ECD. 
In the current study, our aim was to see if there is an effect of the technique of DALK surgery (big bubble versus microbubble techniques) on the percent change of the ECD postoperatively.

No statistical difference was seen between the mean rank of percent ECD change of both the big bubble and the microbubble, with a $P=0.126$, denoting little effect surgical technique has on the postoperative endothelial cell density.

There was a negative relation between the percent change of mean $\mathrm{K}$ and the percent change of ECD, with $r=-0.45$; this finding was also mentioned by Salouti et al. [27] with the second-order polynomial regression analysis showing a weak but significant association between the postoperative changes in keratometry and postoperative ECD changes [27].

This study has several limitations: first, the small number of patients, resulting of less power due to the smaller sample size. In addition, we did not study some important covariates, such as intraocular pressure in the regression model of the postoperative endothelial cell loss. Finally, possible inherent inaccuracies in automatic optical measurements of endothelial cell profile might confound the outcomes.

In conclusion, our results show that ECD are not affected by failure of the big bubble to form and continuing DALK via the microbubble technique.

\section{Data Availability}

Data used to support the findings of this study are available from the corresponding author upon request.

\section{Disclosure}

The authors alone are responsible for the content and writing of the paper.

\section{Conflicts of Interest}

The authors report no conflicts of interest.

\section{References}

[1] V. Jhanji, N. Sharma, and R. B. Vajpayee, "Management of keratoconus: current scenario," British Journal of Ophthalmology, vol. 95, no. 8, pp. 1044-1050, 2011.

[2] F. R. Ghosheh, F. A. Cremona, C. J. Rapuano et al., "Trends in penetrating keratoplasty in the United States 1980-2005," International Ophthalmology, vol. 28, no. 3, pp. 147-153, 2008.

[3] F. Luengo-Gimeno, D. T. Tan, and J. S. Mehta, "Evolution of deep anterior lamellar keratoplasty (DALK)," Ocular Surface, vol. 9, no. 2, pp. 98-110, 2011.

[4] D. T. H. Tan and Y. M. Por, "Current treatment options for corneal ectasia," Current Opinion in Ophthalmology, vol. 18, no. 4, pp. 284-289, 2007.

[5] W. J. Reinhart, D. C. Musch, D. S. Jacobs, W. B. Lee, S. C. Kaufman, and R. M. Shtein, "Deep anterior lamellar keratoplasty as an alternative to penetrating keratoplasty: a report by the American academy of ophthalmology," Ophthalmology, vol. 118, no. 1, pp. 209-218, 2011.
[6] V. M. Borderie, O. Sandali, J. Bullet, T. Gaujoux, O. Touzeau, and L. Laroche, "Long-term results of deep anterior lamellar versus penetrating keratoplasty," Ophthalmology, vol. 119, no. 2, pp. 249-255, 2012.

[7] M. Anwar and K. D. Teichmann, "Big-bubble technique to bare Descemet's membrane in anterior lamellar keratoplasty," Journal of Cataract and Refractive Surgery, vol. 28, no. 3, pp. 398-403, 2002.

[8] V. Sarnicola and P. Toro, "Blunt cannula for descemetic deep anterior lamellar keratoplasty," Cornea, vol. 30, no. 8, pp. 895-898, 2011.

[9] O. S. Arslan, M. Unal, I. Tuncer, and I. Yucel, "Deep anterior lamellar keratoplasty using big-bubble technique for treatment of corneal stromal scars," Cornea, vol. 30, no. 6, pp. 629-633, 2011.

[10] M. Unal, B. Bilgin, I. Yucel, Y. Akar, and C. Apaydin, "Conversion to deep anterior lamellar keratoplasty (DALK): learning curve with big-bubble technique. Ophthalmic surgery, lasers imaging off," Journal of the International Society for Imaging in the Eye, vol. 41, no. 6, pp. 642-650, 2010.

[11] E. A. Archila, "Deep lamellar keratoplasty dissection of host tissue with intrastromal air injection," Cornea, vol. 3, no. 3, pp. 217-218, 1984.

[12] G. K. Chau, S. A. Dilly, C. E. Sheard, and C. K. Rostron, "Deep lamellar keratoplasty on air with lyophilised tissue," British Journal of Ophthalmology, vol. 76, no. 11, pp. 646-650, 1992.

[13] J. Sugita and J. Kondo, "Deep lamellar keratoplasty with complete removal of pathological stroma for vision improvement," British Journal of Ophthalmology, vol. 81, no. 3, pp. 184-188, 1997.

[14] S. Riss, L. M. Heindl, B. O. Bachmann, F. E. Kruse, and C. Cursiefen, "Microbubble incision as a new rescue technique for big-bubble deep anterior lamellar keratoplasty with failed bubble formation," Cornea, vol. 32, no. 2, pp. 125-129, 2013.

[15] W. M. Bourne, L. I. L. Nelson, and D. O. Hodge, "Central corneal endothelial cell changes over a ten-year period," Investigative Ophthalmology and Visual Science, vol. 38, no. 3, pp. 779-782, 1997.

[16] W. M. Bourne, "Cellular changes in transplanted human corneas," Cornea, vol. 20, pp. 560-569, 2001.

[17] D. Böhringer, T. Reinhard, H. Spelsberg, and R. Sundmacher, "Influencing factors on chronic endothelial cell loss characterised in a homogeneous group of patients," British Journal of Ophthalmology, vol. 86, no. 1, pp. 35-38, 2002.

[18] I. Bahar, I. Kaiserman, S. Srinivasan, J. Ya-Ping, A. R. Slomovic, and D. S. Rootman, "Comparison of three different techniques of corneal transplantation for keratoconus," American Journal of Ophthalmology, vol. 146, pp. 905-912, 2008.

[19] V. M. Borderie, P. Y. Boëlle, O. Touzeau, C. Allouch, S. Boutboul, and L. Laroche, "Predicted long-term outcome of corneal transplantation," Ophthalmology, vol. 116, no. 12, pp. 2354-2360, 2009.

[20] Y. Y. Y. Cheng, N. Visser, J. S. Schouten et al., "Endothelial cell loss and visual outcome of deep anterior lamellar keratoplasty versus penetrating keratoplasty: a randomized multicenter clinical trial," Ophthalmology, vol. 118, no. 2, pp. 302-309, 2011.

[21] L. A. Kirkpatrick and B. C. Feeney, A Simple Guide to IBM SPSS Statistics for Version 20.0, Cengage Learning, Wadsworth, OH, USA, 2013.

[22] A. Panda, L. M. Bageshwar, M. Ray, J. P. Singh, and A. Kumar, "Deep lamellar keratoplasty versus penetrating keratoplasty for corneal lesions," Cornea, vol. 18, no. 2, pp. 172-175, 1999. 
[23] J. Shimazaki, S. Shimmura, M. Ishioka, and K. Tsubota, "Randomized clinical trial of deep lamellar keratoplasty vs penetrating keratoplasty," American Journal of Ophthalmology, vol. 134, no. 2, pp. 159-165, 2002.

[24] E. Morris, J. F. Kirwan, S. Sujatha, and C. K. Rostron, "Corneal endothelial specular microscopy following deep lamellar keratoplasty with lyophilised tissue," Eye, vol. 12, no. 4, pp. 619-622, 1998.

[25] B. T. H. van Dooren, P. G. H. Mulder, C. P. Nieuwendaal, W. H. Beekhuis, and G. R. J. Melles, "Endothelial cell density after deep anterior lamellar keratoplasty (Melles technique)," American Journal of Ophthalmology, vol. 137, no. 3, pp. 397-400, 2004.

[26] R. A. Eiferman and E. L. Wilkins, "The effect of air on human corneal endothelium," American Journal of Ophthalmology, vol. 92, no. 3, pp. 328-331, 1981.

[27] R. Salouti, M. Masoumpour, M. H. Nowroozzadeh, M. Zamani, M. Ghoreyshi, and G. R. J. Melles, "Changes in corneal endothelial cell profile measurements after deep anterior lamellar keratoplasty for keratoconus," Cornea, vol. 32, no. 6, pp. 751-756, 2013. 